\title{
Talking Back at the Centre: Demotic Language in Contemporary Scottish Fiction
}

\author{
Jeremy Scott \\ University of Kent
}

\begin{abstract}
This article attempts a survey of a common trend in contemporary Scottish fiction (1994-2003): a unifying concern with issues of 'voice' in narrative. The survey proceeds from an assumption that many Scottish writers make use of so-called demotic voices within their work (i.e. sociolects and dialects from everyday situations, or 'street language'). Very often, this concern with the demotic arises out of ideological standpoints peculiar (arguably) to Scotland: attempts to create a distance from Standard English, a nationalist position, or the ambition to reassert the primacy (or, at least, the equivalency) of oral over written forms of language. The conclusion must be that choices made with regard to narrative technique are ideological choices, and that the demotic method is not without its pitfalls. This assertion is demonstrated through an exploration of three writers: James Kelman, Alan Warner and Anne Donovan. All of these demotic techniques are aided and abetted by the writer's intense identification with place, with Glasgow (for Kelman and Donovan) or with Scotland as a whole, and the intrinsically 'polyphonic' conditions which exist there, i.e. a range of dialects and voices standing as 'other' to Standard (colonial?) English. The writers' goal is to exploit the particular cultural and linguistic conditions peculiar to the country in order to produce a narrative art form which could adequately aspire to represent them; in other words, to create a distinctive literary voice the better to represent a particular regional or national constituency. The pitfalls need to be addressed too: a tendency towards the mundane and repetitive in demotic narratives, a certain belligerence which can alienate readers and the essential question of who this writing is written for. Can it be read with true engagement outside of its target constituency? If not, is such writing open to the charge of parochialism?
\end{abstract}

The whole, healthy language starts up suddenly and noisily as if rising from underwater. Come on, Sauchiehall Street, speak me!

C'moan, Sauchiehall Street, speik me! ${ }^{1}$

... This hail leid pouts.

\section{Introduction}

This survey is written in response to an observation that a significant proportion of British, and especially Scottish, fiction of the last twenty years 
has made use of a demotic narrative voice as the principal register of the text; prominent examples from Scotland include James Kelman, Irvine Welsh, Alan Warner, Anne Donovan, Duncan McLean and Jeff Torrington. The narrative voices of these novels are taken from a quotidian context, making using of regional or urban dialect, and they vary widely in effect. Some, written in a spoken register, can be read as dramatic monologues, some aspire to represent the workings of consciousness, and some are located between these extremes - between the external and the internal, between the 'objective' narration of the implied author and the subjective response of character. When novels of this type are examined as a group, a single and unifying tendency can be discerned: the text's narrative voice attempts to evolve away from the controlling authorial position, with its accompanying narrative discourses of authority, traditionally written in Standard English, and towards the agency of character, using that character's 'authentic voice'. However, it will be argued here that this ambition to narrow the gap between author and character through the discovery of a shared voice also has its roots in various interconnected ideologies peculiar (arguably) to Scotland: the narrative voice will attempt to establish and emphasize a difference and distance from Standard English (a broadly nationalist, anti-colonial position), or the ambition to reassert the primacy (or, at least, the equivalency) of oral over written forms of language, or of the demotic over the so-called 'hieratic' (or literary). In other words, the authorial voice of the classic realist text is seen as representing the oppressor, while the voice of character seeks to speak for the oppressed.

The complex technical difficulties which arise from this ambition, however, are numerous, and spring in part from the attempt to write through the sensibility (or consciousness) of a fictional character with a view to representing the contents of their consciousness through the distinctive idiolect of their spoken voice - creating a tension between internal and external, between 'thought' and 'speech', and between the written and the spoken. The conclusions of this survey are two-fold, then: firstly, that the technical choices a writer makes are very often (and necessarily) ideological choices, and secondly, that use of the demotic as the principal voice of a work of fiction is not without its pitfalls. The three authors to be examined in this connection are James Kelman, Alan Warner and Anne Donovan.

\section{James Kelman's How Late It Was, How Late}

Kelman's particular 'urban' brand of realism is achieved partly through the novel's use of a demotic Glaswegian for the principal narrative discourse; his ambition is to write a constituency in the language of that constituency. Additionally, the very motivation to explore this fictional territory springs largely from pressing socio-political concerns engendered by the perceived suppression of that constituency's voice by the establishment, and from a passionate (and controversial) belief on Kelman's 
part that Standard English, third-person, omniscient narrative can never act as a 'transparent' window into the world of the fiction, as is often tacitly assumed in the case of the classic realist text. Rather, he sees it as ideologically compromised, distorting, essentially alien to a Scottish context, and hence inadequate for the task of authentic fictional representation of his world. ${ }^{2}$ Kelman's novel clearly enacts the precepts laid out by Bakhtin as follows, for its ideological standpoint is embodied explicitly in the manner in which it has been written:

The study of verbal art can and must overcome the divorce between an abstract 'formal' approach and an equally abstract 'ideological' approach. Form and content in discourse are one, once we understand that verbal discourse is a social phenomenon - social throughout its entire range and in each and every of its factors, from the sound image to the furthest reaches of abstract meaning. ${ }^{3}$

The novel is its own message, rather than simply a messenger.

It will be useful in the first instance to provide a short synopsis of the novel's plot. How Late It Was, How Late (hereafter HLIW) tells the story of a Glaswegian, Sammy Samuels, and the almost-Kafkaesque nightmare into which he awakes after a night on the town. The novel opens with Sammy's coming to after a drink-induced blackout, disorientated and trying desperately to piece together the events of the previous few alcohol-sodden days. Sammy becomes the victim of formless and incomprehensible circumstance, like a Joseph K or a Gregor Samsa; after getting into a fight with some passing plain-clothes police officers, he is given 'a doing' and wakes up to find that he has lost his sight. After temporarily escaping the clutches of the police, Sammy struggles home to find that his partner, Helen, has mysteriously vanished, and if she has left an explanatory note, Sammy is, of course, unable to find or read it. Finally, Sammy escapes his situation by leaving Glasgow, bound, the reader is led to believe, for England. The novel ends with Sammy clambering into a taxi: 'The driver had opened the door. Sammy slung in the bag and stepped inside, then the door slammed shut and that was him, out of sight.' ${ }^{4}$ The last three words, too, are instructive: 'out of sight' in a literal sense (through his blindness) and 'out of sight', at last, of the prying eyes of the reader, who at times is made to stand in for the eyes of the ubiquitous system which Sammy is helplessly fleeing - the shadowy 'powers that be' who desire and need to know all and the omniscient narrator of classic realism who accedes to these demands.

Without the benefit of vision, Sammy seems all the more isolated, cut off from the fictional world he inhabits, and yet, paradoxically, must represent for the reader. Thus, the reader is forced to experience the same condition; the lack of speech-signalling verbs means that the reader, just like Sammy, spends much of the time unaware of the source of the novel's voices, i.e. of who is speaking, and to whom. Kelman must thus tackle the problem of simultaneously representing inner and outer details - the former confined traditionally to first-person narrative modes, the latter to the omniscient third-person perspective. He attempts to solve this by inhabiting an 
intersection between 'inner' and 'outer', between first- and third-person, and allowing the narrative voice to fluctuate between the two.

The novel opens as follows:

Ye wake in a corner and stay there hoping yer body will disappear, the thoughts smothering ye; these thoughts; but ye want to remember and face up to things, just something keeps ye from doing it, why can ye no do it; the words filling yer head: then the other words; there's something wrong; there's something far wrong; ye're no a good man, ye're just no a good man. Edging back into awareness of where ye are: here, slumped in this corner, with these thoughts filling ye. And oh christ his back was sore; stiff, and the head pounding. He shivered and hunched up his shoulders, shut his eyes, rubbed into the corners with his fingertips; seeing all kinds of spots and lights. Where in the name of fuck ... (p. 1)

Already the salient features of Kelman's narrative technique are clearly visible. Firstly, and most obviously, there is an attempt to represent demotic Scottish speech (phonetically notated in words such as 'ye', and in the lower-case 'c' of 'christ' - even capitalization becomes politicized). Then, there is the breaking down of traditional syntax through the convoluted and flowing sentence structure associated with representations of consciousness in, for example, the work of James Joyce and Virginia Woolf. The other feature of note here is the mixture of internalized utterances by the character (which Rimmon-Kenan has referred to as free direct discourse ${ }^{5}$ ), for example, 'Where in the name of fuck ...', with diegetic functions (erlebte Rede, or free indirect discourse ${ }^{6}$ ) carrying out the function of narration from a third-person perspective - 'He shivered and hunched up his shoulders, shut his eyes, rubbed into the corners with his fingertips; seeing all kinds of spots and lights' - yet reported using the same idiolect as the protagonist. From hereon in, this kind of narrative voice will be referred to as skaz. (For a more detailed definition of skaz, see Paul Cobley's Narrative (2001).)

Kelman, then, replaces what he perceives as the fatally compromised opacity of a Standard English narrative voice with this demotic Scots, aligning the voice with character rather than author. As a result, there is, ostensibly, no controlling and dominant narrator, and for Kelman this is the only authentic (or ideologically acceptable) mode of authorship. In other words, the traditional omniscient third-person narrator has been superseded. The voice of $H L I W$ is attempting to break free first from a political and social subjugation (in a wider culture where it is abjured) - and then from subjugation by its author. It could be argued that, in effect, Sammy Samuels is 'narrating himself', and the central character of the novel now tells his own story in his own voice. Kelman has explained the technique as follows in interview:

KM: You've stated that you're trying to obliterate the narrator, to get rid of the narrative voice.

JK: Not every narrative voice, just the standard third party one, the one that most people don't think of as a 'voice' at all - except maybe the voice of God 
- and they take for granted that it is unbiased and objective. But it's no such thing. Getting rid of that standard third party narrative voice is getting rid of a whole value system. ... Let's just get to the factual reality here. ... So in a sense, getting rid of the narrative voice is trying to get down to that level of pure objectivity. This is the reality here, within this culture. Facticity, or something like that. ${ }^{7}$

As suggested already, Kelman's motivation for ridding his novel of this patriarchal and paternalistic omniscient narrator and replacing its traditional standard English voice with a demotic Glaswegian stems from a form of socialist political ideology as much as from any overt preoccupation with aesthetics or the poetics of narrative. A common theme can be discerned running throughout his work, from the early short stories to his latest novel You Have to be Careful in the Land of the Free (2004): a concern with the world of the working class, its language, and the assaults which this world and language face from various vested interests, be they political, economic, cultural or otherwise. Kelman's goal has always been to give a credible literary voice to a voiceless constituency by virtue of a flagrant and often polemical challenge to perceived authorities and conventions (literary as well as political), and in the face of a literary and political class whose vested interests, in Kelman's view, will only continue to prosper if that voice is stifled - in other words, if 'proprieties' continue to be 'observed'.

His writing positions itself firmly, proudly and defiantly as 'other' to the so-called canon of English Literature, and it defines its territory linguistically, culturally and socially - as well as geographically. By deliberately placing clear ideological and aesthetic water between itself and the English 'mainstream', Kelman's novel attempts to confront certain perceived ideas about language, voice and identity within These Islands by writing against a centre monopolized by their dominant language and attempting to challenge its hegemony. This centralized language is, of course, the standardized spoken language of the English, previously called 'The Queen's English', or 'BBC English'. Perhaps it would be more accurate, though, to replace the word 'language' with sociolect, for Kelman is not simply attacking the externally imposed language of a colonial oppressor (which, after all, he speaks himself), but the 'accent of economics' (or class) which has various insidious effects, or even, he might argue, a consciously sought-after goal. For Kelman, at the very best this goal is the ignoring and devaluation of marginal voices. At its worst, it is the effective eradication of a national and a class culture.

When I first started writing I wanted to write stories about my own culture and I took it for granted that was what a writer was supposed to do. And it IS what a writer is supposed to do. The trouble is, when you come from our kind of hierarchal society then you don't have the kind of freedoms you'd expect. If you want to be an artist you can be, but the reality is something different.... I'm only allowed to be a writer if I'm willing to give up my culture, give up my wee voice, give up the songs of my grandparents because it's all inferior - it's 
supposedly all childish nonsense and now I'm expected to talk like the fucking king ... ${ }^{8}$

The issue is often seen as a nationalist one, for example by critics such as Ian Bell, who writes: 'If the state of Scotland imposes specific and rather daunting responsibilities on its writers, then Kelman at least is living up to them. ${ }^{9}$ However, the division of such sociolinguistic issues along national lines within the United Kingdom is problematic, not least because it can surely be argued that the voice of the Scottish working class constituency has been suppressed not only by the colonial ambitions of an English-dominated British project, but by the economically dominant social groups within Scotland itself. Furthermore, this suppression and oppression can be identified just as readily within England and Wales too, and therefore is not a peculiarly Scottish condition; the voices of working class Newcastle, Cardiff, Liverpool and Birmingham have been just as marginalized or patronized by 'the establishment' as those of Glaswegians. The obverse view to this is that in the case of English regional voices, the marginalization has not been imposed from outside the country's own borders and can be viewed as less nefarious. The paradoxes surrounding this issue are illustrated by the following illuminating story told by Andrew O'Hagan in his review of HLIW:

I recently took part in a television production devoted to Kelman's work. I arrived at the Glasgow production office when the film was more or less ready. There was a young woman there who was red-eyed and depleted from weeks of work on the programme; she'd clearly knocked her pan in trying to get it into some sort of decent shape, under the usual pressures. As I looked at her scurrying and typing and phoning and thinking, a guy told me of how they'd been fighting the executive, who'd only allow 17 'fucks' to be aired in the show. The tired woman and her colleagues had clearly fought for every one of them.

Then he told of Mr Kelman, who gave the impression he was annoyed by the number of non-Scots working in the production office; so to save any trouble a Glaswegian boy was brought from downstairs, from another office, said my informer, just to sit and answer the phone in case He rang. Sometimes, when you ponder the power of the marginalised artist in this down-treading kingdom of ours, you have to laugh. ${ }^{10}$

It can certainly be agreed, then, that a Scottish voice is made distinct from an English one, not only as an accent or dialect of English, but also at a much more fundamental linguistic level. The 'nationalist' approach to the issue would appear to run as follows: different languages co-exist to a greater or lesser extent in Scotland (Scots, Irish and Scottish Gaelic, Standard English), creating an ideal breeding ground for the dialogism which many critics have found thriving in Kelman's work. In other words, the language of an author writing from a Scottish perspective will already be more linguistically self-conscious (aware of language as utterances in a highly dynamic linguistic context) and more 'multi-voiced' than that of a writer from England. Roderick Watson has written in support of this viewpoint: 
These changing registers and multiple voices have long been available within the Scottish literary tradition, once again because of the peculiar status of Scots as a site of polyphony and ideological struggle in which in Bakhtin's words, 'every object, every concept, every point of view, as well as every intonation' is 'seen from the outside." 11

The language is subjected to scrutiny 'from the outside' because it is located (deliberately or unavoidably) on the margins, and therefore, by definition, finds itself positioned writing back defiantly at the centre.

It follows from all this that demotic fiction proposes a distinction between that which is 'written' (and therefore, as dictated by the establishment, written in Standard English) and that which is 'spoken', which remains untainted, owned by the individual and thus authentic. As Kelman writes in a recent essay, he sees 'the distinction between dialogue and narrative as a summation of the political system'. ${ }^{12}$ There is, however, a counter argument to this view through an appeal to literary convention, and will be illustrated by an analogy to the traditional Japanese puppetry form, Bunraku. In Bunraku puppetry, puppeteers control large and highly complex puppets, but are present 'on stage' behind their puppets rather than hidden behind curtains, under tables or above the stage as is traditionally the case in a Western context. However, the audience chooses not to notice the Bunraku puppeteers (where a Western audience might not so easily accept their being visible) due to the fact that, through the education of convention, its (the audience's) attention is focussed entirely on the activities of the puppets; it adjusts its range of vision accordingly to effectively ignore the puppets' manipulators (who clothe themselves in dark colours). Arguably, the diegetic narrative modes of much narrative fiction makes use of exactly the same convention, and anticipate the same 'adjustment of focus' on the part of the reader; like the puppeteers, convention can dictate that the controlling narrative voice be viewed as an enabling device, and as an essential (and unavoidable) medium if the 'information' of the novel or story is to be mediated and conveyed. In short, it is intended to be formally indiscernible. Thus, to suggest that a narrative voice in Standard English somehow alienates the working-class Scottish reader could be construed, in fact, as acutely patronising, as the suggestion implies that the reader is unable to respond to this convention. It could be argued, then, that the explicit assertion that Standard English can never be transparent because it is ideologically compromised is highly problematic. Examples from HLIW itself should serve to illustrate this point:

He groped his way around, kicking forward with his feet, and he reached the wall. He got down on his knees to feel the floor, cold but firm, cold but firm. The palms of his hands flat on it; he had this sensation of being somewhere else in the world and a music started in his head, a real real music ... (p. 11)

Or later: 
Sammy had stopped, he turned to the tenement wall and leaned his forehead against it feeling the grit, the brick, he scraped his head along it an inch or two then back till he got that sore feeling. (p. 37)

These are examples of Kelman's demotic narrative voice, yet they are also clearly Standard English. It is extremely difficult to delineate clearly and with confidence between the two discourses, as they are not distinct. Standard English, it could be argued, can be accepted simply as a neutral medium of communication, which stands equally for all the various spoken forms of the language. Duncan McLean has argued in support of exactly this view: 'Standard English spelling stands equally for all dialects - I'm not willing to let Standard English become any more firmly associated with a single accent/dialect than it is already. ${ }^{13}$

Kelman would presumably disagree, yet, as illustrated, he seems to tacitly acknowledge that Standard English is inescapable at certain points in the narrative. Perhaps it is slightly inappropriate to decontextualize the above segments from the wider narrative. Kelman might argue that they absorb the wider demotic tone through a kind of 'osmosis', through being surrounded by it, and should be viewed as representing that voice despite the Standard English orthography - in which case, surely, he partly accepts the validity of the conventional response outlined above. Nevertheless, it is still true that if the reader were to follow Kelman's principles to their logical conclusion, they would adjudge many parts of the novel's narrative discourse to be ideologically and stylistically 'offside'. The reason that the diligent reader will not do so is precisely because he or she accepts the very convention of transparency which Kelman is attempting to renegotiate. He or she takes up the principles of an implied bargain which is made between artist and audience across a range of art forms (from Bunraku to Shakespeare): that to participate in this work the audience must accept a number of artificial conventions - that the puppeteers are invisible or that no one but the audience can hear Hamlet's soliloquies.

\section{Alan Warner: Morvern Callar and The Sopranos}

Alan Warner is an author exercised by very different concerns to those of Kelman, yet confronted by similar technical problems. In the first place, he seems to take less notice of the 'responsibility' (identified by Bell) to Scotland and its language which Kelman so avidly takes on and his writing stems from no obvious nationalist impetus, as the following remarks show:

'It's the most fucking unbelievable country,' Scots novelist Alan Warner says of his homeland. 'It's a philistine and racist place ... we come down here and pretend it's God's Calvinist country and slag you off, but the level of discourse up there is incredibly poor. People like to pretend there's some kind of artistic renaissance in Scotland. A renaissance is something that happened in Italy over a period of 200 years.' 
I had always imagined Warner wearing some gaudy Braveheart tartan on his sleeve, coupled with a prolier-than-thou persona; instead, he says he's 'very fed up with being bunched with that whole Scottish thing'. ${ }^{14}$

Warner, it would seem, uses the demotic for its expressive effects and creative potentialities rather than out of a desire for ideological credentials. Secondly, rather than ignoring the hieratic like Kelman out of a diffidence to the idiolect of a character, Warner shows great delight in the lyrical potentialities of language and attempts a fusion of the demotic and the hieratic. Where Kelman has alighted upon skaz as an answer to various methodological and ideological objections to the classic realist text, Warner's prose-poetry effectively begs these questions by producing a very different kind of technique.

Warner's narrative voice is a complex hybrid. On the one hand, there is a subtle allegiance to the tones and range of a Scottish demotic (in this case, of Argyllshire and the Western Isles); on the other, there is a clear impression of a writer straining against the expressive limitations imposed (arguably) by this idiom and indulging a desire to 'ascend' towards the lyrical. The reader is spectator to a constant tug of war between an overarching demotic discourse and an undoubtedly accomplished and beguiling hieratic tone; i.e. between the prosaic and the poetic. Despite Warner's public distancing of himself from 'that whole Scottish thing', he too is clearly desirous of creating a literature firmly rooted in a specific geographical and cultural space, as well as in the language of that space. He elects to ignore Kelman's skaz, based on an orientation towards the idiolect of character, for a far more author-oriented narrative discourse. This implies a fundamental shift in perspective: from that of character to that of author, despite, in his first two novels, the adoption of what appears to be an overtly internalized and subjective point of view.

Warner's influences can be traced to his contemporaries, especially to the work of Kelman, Duncan McLean and, to a lesser extent, Irvine Welsh; however, as has been suggested, his motivation is less a form of nationalism than a wish to explore the viability of the demotic as narrative discourse, partly out of a hedonistic delight in its cadences. Warner, then, takes certain elements of Kelman's urban realism whilst discarding others in favour of a more mellifluous prose which aims to combine the demotic with an almost-expressionistic quality of observation. There is a huge gulf between the phlegmatic, Hemingway-like 'facticity' of Kelman's earlier stories and Warner's vivacious prose-poetry. Mars-Jones differentiates Warner's work from that of Kelman, Gray and Welsh, terming Warner's a 'non-urban' approach to the genre, and explaining the dangers of any attempt to make generalized statements about contemporary Scottish writing:

Nobody who writes a novel can be described as unliterary, but these three writers hardly share a sense of tradition: Gray seems happy that his novels should be read by people who read novels; Kelman would like to write a book so stark and urgent that it acquired an authority beyond that of fiction, and Welsh aims at 
having his books read by people who don't read books. Alan Warner ... is different again. These Demented Lands has no time for the urban Scotland that is assumed to be the subject matter of a modern writer: the action takes place on an unnamed island, and offhand references to 'the Central Belt' are as close as Warner comes to the names Edinburgh and Glasgow (the word 'Scotland' itself is also under embargo). One character, asked if he is a city man, replies 'Mainland', and is told, 'That's grave enough, my friend'. ${ }^{15}$

His first novel, Morvern Callar, is the story of a 21-year-old orphan working as a shelf-stacker at a local supermarket and living with a mysterious middle-class writer and drop-out, referred to only as 'Him'. The novel opens with Morvern waking up one day around Christmas on the floor of the flat she shares with 'Him' to discover that he has committed suicide; however, rather than calling the police, she goes out, telling only her best friend that He has left her. So begins a drunken, drug-fuelled hyper-bildungsroman that leads to London and the Spanish coast, before she returns, pregnant and penniless, to Oban.

The novel is written in a multi-textured, first-person discourse that takes as its source not just a Scottish demotic but also the peculiarities of Morvern's personality; for example, her almost-childlike outlook upon the world and her equally intense expressions of emotion. Her simple, understated analysis of the way she reacts to the tragedy of her boyfriend's unexplained suicide is representative of this aspect of her sensibility:

I started the greeting on account of all the presents under our tree and Him dead. Useless little presents always made me sad. I start for me then move on to everybody when I greet about the sad things. Her from Corran Road with all sons drowned off the boats. She bubbled till she lost an eye. I greeted in heaves and my nose was running. ${ }^{16}$

Other idiosyncrasies of Morvern's oral register emerge in the names she gives to the other characters who inhabit her world. Her socialist stepfather is 'Red Hanna', her marauding and sanctimonious boss at the supermarket 'Creeping Jesus'; other acquaintances mentioned are 'Smiler', 'Ramraider', 'Smugslug' and 'Shadow'. The reader's impression of her world, then, is intensely mediated by a highly subjective viewpoint - and one which is, in ambition and intent at least, devoid of any authorial presence, satisfying the demands of what Warner calls, with echoes of Kelman, 'that objectivity'. ${ }^{17}$ Morvern also distorts and fractures the English language, the better to reflect her refracted sensibility; she invents new nouns in a distinctly Joycean fashion by adding the suffix '-ness', as in 'nighttimeness' and 'summerness', and makes use of countless elisions and solecisms ('the tousled strips of orange peel among' and 'a layer of heat on top me'). Indeed, the most engaging (and paradoxical) use of Morvern's voice comes in the highly descriptive passages of the novel. Morvern's rendering of the environs of the port is notable in this respect, making use of evocative and resonant place names and vivid depictions of colour, sounds and smells. 
In fact, it could be argued that Warner never allows his character to 'feel' in any authentic manner; there is a definite sense that the author is doing all the feeling for her and on her behalf; arguably, then, there is no character, only an author's highly distinctive voice. The very density (even virtuosity) of Warner's lyricism eclipses any responses from Morvern the Character herself; perhaps, far from achieving 'that objectivity', Warner is stepping in to speak for Morvern's sensibility with a highly poetic style. At best, Warner speaks directly for her impressionable sensibility, whilst she speaks her own thoughts; however, rather than coalescence, it is often possible to detect an interference, a straining at the leash imposed by the demotic, an infection, or more probably an obliteration, of a mannered yet mimetically acceptable idiolect of Morvern by the explicitly writerly, hieratic register of a poet-novelist. As Fiennes comments:

She [Morvern] observes 'peacocks' eyes of olive oil skimming atop the vinegar, dapples of black pepper and tawny streaks of mustard popped onto the biggest piece of lettuce'. 'Peacocks' eyes', 'dapples', 'tawny' - all signature notes of the mandarin sensibility of an Updike or Nabokov. ... Morvern's voice has been praised for its originality, but being original is not the same as being true: her prose is a trick, an artful ventriloquism. ${ }^{18}$

Another example occurs in the section where Morvern goes night swimming off the coast of the (unidentified) holiday resort:

All was made of darkness. My chest showed out the oily black surface. I angled my toes round so the moon was rising right out between my bosoms. I let the coldish surface of the water cluck around my ears so's I was looking straight up at the sky. Stars were dished up all across bluey nighttimeness.

I let my legs sink down; my nudeness below in the blackwater; legs hung in that huge deep under me and the layer on layer and fuzzy mush of star pinpricks were above with the little buzz of me in between. (Morvern Callar, p. 208)

As the voice of Morvern Callar runs out of lexical space, so the writerly sensibility of Warner takes over. The moments of beauty are stage-managed, imposed by an author rather than emanating from an intricately defined character. In other words, it may be a difficult and dangerous thing for the educated novelist to deign to speak for his working-class characters in this way, and something which Kelman, on the whole, explicitly seeks to avoid.

In The Sopranos (hereafter TS), Warner turns to a third person register in the past tense and to a voice which is omniscient, all-seeing, impartial and unidentifiable; yet, crucially, it forswears the lyrical asceticism of Kelman's skaz. Like the Sammy-narrator, this voice too speaks at times with the same demotic idiolect as the characters, but it is once again refracted, contorted and saturated by Warner's own explicitly authorial (and often beautifully rendered) lyricism. Robert Crawford, writing in The Independent, described the narrative situation thus:

[Warner's prose is] a combination of muck and brio that is all his own. The scatological and the delicate are fused in a tale that confirms Warner's status as 
the Rimbaud of Argyll. As often in post-James Kelman Scottish fiction, the narrator's voice can sound at times like the characters' speech. But the poetry of Warner's text goes hand in hand with an unKelmanly hedonistic impulse. Morvern Callar astounded not least because of its male-authored, thrill-seeking female narrator. Much of the time in The Sopranos, Warner reserves for his genderless third-person voice a sensibility and reach denied to most of his characters...The style is an art-speech suggesting vernacular Scots English ... The English language is rule-breakingly adjusted to the environment. ${ }^{19}$ (my emphasis)

Art-speech is, as will be seen, a very useful term to define the narrative methodology and resulting 'folk' discourse upon which Warner alights in this novel, and will be used here to distinguish this methodology from skaz; yes, there is a definable narrator whose speech resembles that of a character in the novel, but, as will be seen, the characters and this narrator occupy very distinct and separate spaces in the text.

A typical example of the blend of the hieratic and the demotic to which Crawford refers is found immediately at the opening of the novel. Just as in $H L I W$, it is hard to distinguish where narration ends and direct speech begins for, like Kelman, Warner has dispensed with speech-signalling punctuation marks - speech and writing have equal precedence.

Up back everything was moving into post-seventh-Hooch-syndrome. The two bottles, that were really a half bottle Southern Comfort lightly diluted with the Coke that hadn't gone down the toilet, were passed back and forth in an alliance of giggles and silence.

The bus was slithering and swaying into the Low Lands - instead of the impossible places, the ground now became creamy pastures; high walls, the mosses killed by city-nearness, came up close to the window - beyond the racing top bricks, the rhododendron estates of great, mysterious wealth. ${ }^{20}$

This, then, is a third-person voice granted stylistic freedom (and which sounds uncannily like the voice of Morvern Callar); in a reverse of the narrative situation of HLIW it is released from the restrictions of a character's voice to which Kelman voluntarily accedes, and by which Warner was confined in Morvern Callar. However the art-speech of this voice, like the skaz of HLIW, can still blend seamlessly with speech of the characters due to the demotic cadences which they share ('up back', 'post-seventh-Hoochsyndrome'):

No sweat, we'll never win; other choirs sing about Love, all our songs are about cattle or death!

Fionnula (the Cooler) spoke that way, last words pitched a little bit lower with a sexyish sideways look at none of the others. The fifth-year choir all laughed.

Orla, still so thin she had her legs crossed to cover up her skinniness, keeked along the line and says, When they from the Fort, Hoors of the Sacred Heart, won the competition last year, they got kept down the whole night and put up in a big posh hotel and ... everything, no that I want that! Sooner be snogged in the Mantrap. 
Know what the Hoor's school motto is? Fionulla spoke again, from the longest-legs-position on the wall. She spoke louder this time, in the blurred, smoked voice, It's 'Noses up ... knickers DOWN'! (TS, p. 1)

If Fionulla (the Cooler) speaks 'that way', then Warner's omniscient narrator takes its lines from the same style sheet - and then evolves them through a lyrical 'heightening'. However, crucially, it appears that the voices of the characters themselves are leaching into the narrative discourse rather than the reverse situation of Morvern Callar. Warner, then, has adopted elements of Kelman's skaz; however, the gap between narrator and character has widened due to the former's stylistic indulgences. Where Kelman forswears (almost) any hint of a sublime lyricism out of a fidelity to authentic representation of character, Warner embraces it fervently, and in doing so, embraces the 'paternalistic' authorial voice unabashed.

The technique functions well in the following extract, which is a description of the area around the girls' school, and is conventional in intent but experimental in form:

Our Lady of Perpetual Succour's dead, stone eyes were cast way over the teenagers below. The gaze looked above the slates of McAdam Square and the railway stone clock, to the bay, beyond. She stared constant at some theoretical point, dependent on the angle of the reinforced concrete block Kirklam \& Sons Construction had power-bolted her onto, year she descended from heaven, under a Westland helicopter.

Her left arm was held out with as daft and neverending finality, offertory fingers appealing, though only ever receiving a tiny curlicue of sparrow's dropping; only ever delivering a slow sequence of rain drips to the sheered height way down onto the concrete playground below, where, every September, girls on their first day would bawl up to her: Don't jump things can't be that bad! Don't do it! Suicide's a sin.

That morning, the statue's rampant gaze drove across the surface of the port's baywaters as perusual but, it seemingly settled for once on the long black vessel now anchored there, even the communications aerials on the nuclear submarine's conning tower, no reaching above the cloud-looped summits of the distant island mountains. (TS, pp. 4-5)

The words 'rampant' and 'daft', 'no' for 'not', the solecism of 'she stared constant' and the elision of 'year she descended' could have been spoken by Fionulla or Kylah or any of the pupils; the compound adjective 'neverending' and the neology of 'as perusual' bear obvious shades of Joycean 'unenglishing' of the language, while the first sentence of the extract is clearly written from an external perspective in a 'classic' third-person voice. These elements combine with the poetry of 'slow sequence of rain drops' and 'cloud-looped summits' - but all of it, poetry, demotic cadences and prose, is irredeemably Warner's. Crucially, there is no jarring effect, for there are no competing discourses to jar. The characters' and narrator's vernacular resonances (what one reviewer has called 'teen demotic ${ }^{21}$ ) and the hieratic lyricism coexist peacefully, at ease with each other, in the prose. 
Art-speech, then, can now be defined as an authorial narrative voice which is a hybrid of an idiosyncratic lyricism and the cadences of the demotic. Any 'leaching' of authorial register into the discourse of a character is not a lapse in the representational scheme, but is viewed instead as an opportunity and expressive potentiality to be exploited unrestrainedly. However, this categorically does not address the political, cultural and ideological challenges of Kelman's skaz; rather, it invokes a complete and hedonistic authorial freedom once again. Warner, whose methodology is anathema to Kelman's fervently stated project of authenticity based specifically and categorically on character and place, has after the experimentation of Morvern Callar and These Demented Lands, decided to write a very different kind of novel, based not on a first-person and thus stylistically-restrictive and subjective voice but on art-speech and an implied rejection of the perceived limitations (and simulated transparency) of skaz. So, as he reaches the close of his methodological journey, the puppeteer steps forward to take the applause, unabashed (if a little drunk on power) and profoundly in command of the stage once more.

\section{Anne Donovan's Hieroglyphics}

Sharp, compassionate storytelling that glows with the poignancy of childhood and the joy of a prohibited tongue.

Michael Faber, blurb to Hieroglyphics

It is certainly arguable that demotic narrative techniques function more successfully within the short story genre or in poetry than in longer pieces of writing. The danger of a certain monotony of tone is lessened, and that particular 'concentration' afforded by the compressed narrative of a short story serves to imbue its voice with an extra resonance. Hence, it will be enlightening finally in this survey to consider the short story, and the 2001 collection by Anne Donovan, Hieroglyphics and Other Stories, is an instructive example, written as it is for the most part in the 'prohibited tongue' of a Glaswegian demotic, but containing also examples of more traditional Standard English narrative registers. It would appear that over the course of writing these stories Donovan has found herself experimenting with different narrative techniques in response to the issues discussed thus far.

It becomes abundantly clear to any reader of her work that one of her overriding concerns as a writer is the reclamation of Scots speech from the 'clutches' of Standard English, or rather, an assertion of its legitimacy in the face of the English centre's cultural and linguistic dominance. In this respect her ambition is similar to that of Kelman, but where Kelman approaches this task of legitimising voice from a highly politicized perspective, Donovan operates at a more humanistic level, linking Scots to the need for purely Scottish modes of expression. Her writing portrays Scots as the natural language of feeling and emotion, expressing fundamental psychological aspects of the human condition, whereas Standard English is depicted as the 
language of authority, rationality and logic. In Donovan's writing, Standard English is the embodiment of Bakhtin's definitions of monologic discourse, Scots the expression of its carnivalistic mirror image (and adversary). David Cunningham sums up these issues neatly in his review of Hieroglyphics and Other Stories (hereafter HOS): 'She [Donovan] uses her transitions between dialect and Standard English to illuminate what, for want of a less gloomily sociological phrase, we must call "cultural hegemony". English is the language of education, of authority. ${ }^{22}$ The validity of language for Donovan, then, is linked explicitly and inextricably to its cultural context - in this case, Scotland. For Scots to rely on what is, essentially, a foreign tongue for their expressive needs is incoherent and an anomaly. Rosemary Goring, writing on Donovan's work, is of the opinion that the use of Scots should no longer be simply identified with an explicitly anti-colonial stance. She speaks of 'the sheer sensual pleasure that we get from the language .... and the exhilarating depth of expression it allows us' ${ }^{23}$ and then continues:

At last we seem to be reaching a healthy and forward-looking fusion of language and cultures. Far from being a restrictive or anticolonial choice, writing in Scots represents a broadening of aesthetic possibility as well as the desire to reclaim a sense of ourselves, and our history, that English words alone simply cannot express. As 10 minutes in a school playground will teach you, most Scots are bilingual. Until it becomes acceptable to speak in dialect, whatever our jobs or location, such linguistic ambidexterity will be a fact of life. ${ }^{24}$

Donovan herself has remarked that the Glaswegian working-class voice is 'more a direct line to the heart, you get closer'. ${ }^{25}$ As was argued in the section on Kelman, though, this is not a purely Scottish situation; the degradation of dialects can be found throughout the English regions too, together with the corresponding issues of local identity and cultural legitimacy.

A selection of stories from HOS will here be analysed for the way in which Donovan has applied demotic narrative voices in her writing, paying particular attention to the way in which she has attempted to solve the paradoxes and problems encountered in other writing discussed thus far. Her approach to the issues inherent in the tension between Standard English (as a written language) and oral Scots will also be explored.

The title story of the collection, Hieroglyphics, tells of a young schoolgirl with dyslexia, her accompanying problems in learning to read and write, the cathartic resolution and depth of expression which she finds in drawing small pictures instead and the maddening failure of her teachers to connect (or even attempt to connect) with this idiosyncratic mode of communication. The story is written ostensibly in a mimetic first-person voice, in the first person, with the Scots demotic phonetically rendered: 'Ah mind they [the letters of words on the page] were birlin and dancin roond like big black spiders. Ah couldnae keep a haunle on them fur every time ah thoat ah'd captured them, tied them thegither in some kindy order, they jist kept on escapin. ${ }^{26}$ In addition, this voice must perform diegetic functions. 
For example, in the following quotation the protagonist Mary's actions are conveyed to the reader in a manner which seems comfortably integral to her voice: 'It wasnae my fault, ah didnae mean tae drap the whole load ae it on the flerr' (HOS, p. 1). This piece of narration does not have the same obtrusive effect as a piece of explicitly diegetic narration, as it adequately represents the reflections of a child without stretching the reader's generosity. In short, it does not disrupt the narrative's mimetic functions because it stays (more or less) within the realms of plausibility. Most direct discourse (or speech) in the story is in Standard English, and also is italicized; presumably, this is meant to intensify the impression that it is somehow external to, more artificial and less authentic than, the Scots of the narrator. (In Bakhtinian terms, Donovan's narrative methodology in this story exploits the tension between the two separate heteroglots; therefore her technique is highly dialogized.)

Just learn the rules, pet. Just learn them off by heart.

But they didnae follow oany rules that ah could make sense of. M-A-R-Y. That's ma name. Merry. But that was spelt different fae Merry Christmas that you wrote in the cards you made oot a folded up bits a cardboard an yon glittery stuff that comes in thae wee tubes. (HOS, p. 1)

The ludicrous inconsistencies (bewildering for the learner, be they child or adult) between English orthography and phonetics are also highlighted: 'But how come flerr wisnae spelt the same as merry and ster wis different again and ma heid was nippin wi coff and laff and though and bow, meanin a bit aff a tree. Ah thoat it wis Miss Mackay that wis aff her tree, right enough' (HOS, p. 1).

A dyslexic girl trying to decode the relationship between her version of oral speech (demotic Scots) and its written counterpart (Standard English) is an apposite distillation of corresponding issues explored thus far. To Mary, her 'voice' (internal or external) is paramount, her only means of connecting her inner self to the bemusing and illogical world around her, and the codified, highly structured and monologic systems of the written word are artificial, alien, meaningless and woefully inadequate for the task. The teachers' attempts to impose Standard English on Mary meet with blank incomprehension:

Do you know what hieroglyphics are, Mary?

Aye, sur. It's Egyptian writing.

Yes, sir, not Aye, sir. I is the first person nominative, not that any of you will know what that means, of course, since you no longer have the good fortune to be properly educated in the classical tradition. Maybe if you could learn to speak properly you could then write properly.

$[\ldots]$

So, Mary, if hieroglyphics means Egyptian writing, why do you think I am referring to your script using that term?

Because you cannae ... can't read it, sur. 
Precisely, Mary. And since the function of reading is to communicate, what point is there in writing something which is utterly unintelligible?

Ah jist sat there. (HOS, pp. 5-6)

In HLIW Kelman has forged a narrative methodology in which the written, standardized language transcends oral speech by absorbing it; Donovan's protagonist, on the other hand, bypasses the written, and the methodology implies the need to establish a distance between the act of narration and the notated words on the page. If Mary were able to write her own story down, perhaps she would transcribe her voice partially in the manner Donovan has: by attempting to represent its natural sounds as she hears them rather than unfamiliar structures that must be learnt from an external source. It could be argued, however, that the gap between the pronunciation, grammar and orthography of Standard English and the way their language is spoken aloud exists for every speaker of English, not just Scottish speakers.

Mary finds her 'true' voice through her own individual version of hieroglyphics; she draws small pictures in a sequence, and finally happens upon the only way she can communicate 'in writing'.

Then ah startit daein the hieroglyphics fur real. In the beginning it wis part of oor History project on the Egyptians. We hud tae make up oor ain version, writing wee messages and stories. Miss Niven presented it tae us as if it wis some crackin new original idea [...]. And ah turn toot tae be dead good at it. Somehow the wee pictures jist seemed tae come intae ma heid and it wis that easy compared tae writin words. If ye wanted tae say would you like a cup of tea?, ye jist drew a wee cupnsaucer an a mooth wi an arra pointin at it and a question mark. Nae worryin aboot whit kindy wood it was or how many e's in tea. $(H O S$, p. 7$)$

This passage provides a useful distillation of a central issue: how a writer should communicate an idea, sensation or emotion which may be experienced by a character but which cannot be verbalized (for whatever reason). It is certainly possible that an individual who finds themselves limited by words can express themselves superbly in pictures. A very apt example of this can be found in the case of the Cornish fisherman and painter Alfred Wallis, who was barely literate and in many ways inarticulate; however, he was an extremely imaginative and poetic artist. Mary's 'pictorial' imagination would appear to function in a similar way. To rely, then, on an authenticity of voice alone to represent all facets of a character's inner life is to compromise (or even completely ignore) another authenticity, that of the depth of a character's response to the world around them (their 'sensibility', or their capacity to aestheticize). It would be a mistake for a novelist to represent Alfred Wallis telling his own story in his own words - so much of a complex inner life would be lost 'in translation'. In the same way, the diegetically oriented voice of this narrative at times encounters the extreme difficulties of rendering the internal impressions and sensations of a character in a demotic first-person voice: 
A big rid brick buildin bloackin oot the sky. Spiky railins wi green paint peelin aff them. Hard grey tarmac space wi weans loupin aw ower the place, playin chasies in the yerd, joukin aboot roond the teachers' motors: the big yins, sophisticated, hingin aboot the corner, huvin a fly puff afore the bell goes. And us, wee furst years, aw shiny an poalished-lookin in wur new unfirms (soon tae be discardit), staunin in front ae the main door, waitin tae be tellt where we're gaun. (HOS, p. 3)

This section appears to jar with the rest of the text, for Donovan the author can be seen intervening here to describe the school building for the benefit of the reader, and (ironically given the ideological and linguistic stance of this story) interspersing with Mary's thoughts words and phrases that have an unmistakably alien tone ('sophisticated', 'discardit') and clearly an external perspective ('aw shiny an poalished-lookin'). An authorial, diegetically oriented voice is allowed to take over, momentarily eclipsing the voice of the character-narrator. In a sense, the text enacts the very linguistic issues which it raises. Mary, like Alfred Wallis, is better at communicating pictorially, through highly visual imagery, exposing the limitations of language as a medium capable of adequately expressing the complexities of character. Thus, Donovan's narrative, rooted as it is inextricably in the written, must at times contravene its own principles in order to represent and render its subject matter effectively.

The theme of authentic representation of voice through the written is continued in Virtual Pals. This is the story of another young schoolgirl, Siobhan, who takes part in an email exchange project with a school in Shetland; however, she finds herself corresponding with a student (the exact identity of whom is never revealed) who claims to be from Jupiter, and hence unaware of the facts of linguistic life in Scotland. Donovan transcribes the emails faithfully, with no authorial interjections, in the manner of classic epistolary narrative; however, the adoption of the communication medium of email is significant and has implications for the topics under discussion here. Email occupies a 'no man's land' within the various correspondence mediums, found at a point in between the written letter and the telephone call, and is often written informally, in faithful imitation of the writer's natural speaking patterns, and with scant regard for formalized linguistic conventions. As this is a school project, however, Siobhan's first mail to her new pen friend is self-consciously correct, ritualized and formalized, if still bearing some of the features of a childlike register:

My name is Siobhan and I am in 2C at Allan high School, Glasgow. Our English teacher is getting us to do e-mails to your school in Shetland and we have to tell you about our lifes but because everybody has to get to go on the computer we have to keep it short she says to just put in the most important stuff. (HOS, p. 9)

However, as she warms to her task and after receiving her correspondent's first highly enigmatic reply, she begins to write in Scots. The implication, once again, is that demotic Scots is a more direct route to the centre of emotions, 'to the heart' (as Donovan pointed out in interview), and therefore 
to an authentic view of the self: 'It's pure brilliant to get your e-mail. Your letter was the best reply in the class. Everybody else is jealous they didn't get a penpal from Jupiter and Janine even said she'd gie us a signed Steps tee shirt if I'd swap with her but I'm not gonnae' (HOS, p. 31). The mysterious Jovian pen friend's articulacy and proficiency with language conveniently allow Donovan to articulate one of the central issues relating to language and identity which her fiction sets out to explore:

I am surprised that your teacher thinks that you can learn from my English. Surely the register, vocabulary and syntax of your language is culturally and socially appropriate to your environment and the only reason for using other forms of language is that they are more fitting in a given situation? I appreciate that there are different norms within complex social groupings. (On our planet we do have differences in vocabulary between areas, for example, and some differences between generations too.) However the idea that one form of language is better than the other is foreign to our culture. (HOS, p. 37).

Siobhan's response is instructive in that it is probably illustrative of the attitudes of most young people to their own dialect, and foreshadows the rather dismissive, pessimistic ending of the story: 'I don't really understand what you're on about. Are you saying that the way I talk is just as good as proper English? Try telling Miss Macintosh that. I mean if you want tae make up a Glaswegian dictionary, that's fine, it's a laugh. But it's no right, is it?' (HOS, p. 38). A Chitterin Bite is also double-voiced, but this time the two voices are two depictions illustrating two aspects of the same narrator, one located in the past and one in the present of the story. The character's 'older' voice is in Standard English, and this is thrown into highly dialogic relief by the fact that her childhood voice uses Scots. The implication is clear: abandoning one's original voice leads not only to linguistic and cultural dislocation, but also to dislocation from one's 'true self'.

We'd go tae the baths every Saturday morning, Agnes and me. Ah'd watch fae the windae, alang the grey, gluthery street, till ah caught the first glimpse of her red raincoat and blue pixie hat turning the corner, then ah'd grab ma cossie, wrap it up in the blue-grey towel, washed too many times, and heid for the door. (HOS, p. 61)

The older voice uses a Standard English first person narrative mode in the present tense:

I still go swimming, but now to the warm and brightly lit leisure centre with its saunas and steam rooms, aromatherapy massages and hot showers. Tuesday is Ladies' Night and I drive there in my car; shampoo, conditioner and body lotion tucked away neatly in my designer sportsbag along with a change of clothing. (HOS, p. 62)

Once again, the text enacts and tacitly condemns a linguistic and existential betrayal through its narrative methodology. In most of Donovan's stories, childhood is equated with a state of linguistic innocence and existential integrity. The voices of many of Donovan's characters wait in the anteroom 
of maturity: pre-writing, pre-education, pre-rationalism and pre-conditioning. As the protagonist of $A$ Chitterin Bite abandons the voice of her childhood, so she leaves this prelapserian state and enters the dreaded 'real world'; in short, her linguistic betrayal is meant to represent a betrayal of her younger, and therefore purer, perhaps even truer, self. To extrapolate even further and transfer this ontological situation to a narratological one: abandonment of an intrinsically dialogic demotic voice in favour of a monologic neutral idiom is a betrayal of the deeper, richer potentialities of narrative fiction. Accordingly, towards the end of the story, the narrative moves out of mimetically oriented first-person discourse and towards neutral, diegetic and slightly matter-of-fact narration: 'Steam rose from the spaghetti and the clam shells gleamed dully like slate roof tiles. It smelled wonderful and I was starving. I picked up my fork, twirled the pasta round and round, pressing it against the spoon, and ate' (HOS, p. 70).

The final story to be considered from this collection is The Doll's House, an exploration of father-daughter and mother-son relationships spanning three generations, and the symbol of the doll's house made by the father for the daughter, and then passed on in turn by her to her own son. This story appears to be a culmination (and synthesis) of narrative techniques explored in the pieces preceding it, and, as will be seen, is at times comparable in technical terms to Kelman. The story begins as follows:

Her daddy made the doll's house. She remembered sitting on a high stool next tae him at the green Formica table, watching. She couldnae remember him actually building it, sawing the bits of wood and fitting them intae place, she just remembered his concentration; head bent, the meticulous way he did the details, the fireplace in the living room, the plastic covering on the floors. And most of all, the blood gushing fae her cut thumb when she'd touched some sharp bit of metal she shouldnae have touched. (HOS, p. 85)

This is skaz. The narrative perspective is clearly external to that of character, yet the narrative voice takes on demotic cadences (i.e. is written towards the speech of another). Interestingly, the Scots is diluted in comparison to earlier stories in the collection (in the same way as Kelman's demotic skaz is toned down in relation to some of his initial short stories), and is restricted on the whole to prepositions, negatives and some present participles. A hybrid voice blends the perspectives of protagonist and narrator (and even the speech of other characters) to the point where they become virtually indistinguishable, yet all the while it maintains a third person register. In its fidelity to the speech of its central character, and despite its third-person perspective, this skaz is, like that of $H L I W$, a world away from the authorial art-speech of The Sopranos; at no point does the narrator of The Doll's House trespass into overtly lyrical (and thus authorial) territory - territory through which Warner wanders aloof.

She peeled the sealing strip fae the wee tub, lifted off the top. The paint had separated, swirls of deep purple and white; she had tae stir it round wi a wooden stick. And it was darker than she'd thought. She dipped the brush, started tae 
cover the living room. Maybe it'd dry lighter. You could never tell how a colour would look till you put it on; the pictures on the side were nae use. (HOS, p. 88)

Donovan's concern with the link between authenticity of language and authenticity of self is equivalent to Kelman's even more vehement rejection of a narrative register and methodology imposed by an alien culture from outside the borders of Scotland. She, like Kelman, is asserting the right of Scots to be the language of narration, not simply that of speech. The demotic is just as viable a medium for diegesis (e.g. exposition, stage management, description, or, it could be said, 'mimesis of the external world') as it is for mimesis of thought and utterance. The use of skaz frees her narratives from the constraints of the first-person perspective and allows it to wander between the diegetic ('She dipped the brush') and mimetic ('Maybe it'd dry lighter'), according to the representational purpose each section, paragraph, sentence or even word is required to fulfil.

\section{Conclusion}

Kelman, Warner and Donovan have all been championed by various sections of the media, especially the Scottish and Welsh press. The latter appear to have sensed the existence of similar literary currents in Wales, i.e. an ambition to 'write back' at England and English. Writers such as Niall Griffiths would be a prime example of this tendency, and clear parallels with the Scottish situation can be identified; in short, the experience of location around the margins of a 'dominant' England has been a principal motivation in the evolution of demotic narrative methodologies. The prevalence of this demotic style in Scottish writing is evident in the fact that they and other British (including English) and Irish writers like them (Irvine Welsh, Patrick McCabe, Roddy Doyle, Alasdair Gray, John King, Greg Williams) are well-known, widely read and attract critical acclaim.

One of the chief methodological issues which these writers exploit to creative effect is the correspondence (or lack thereof) between oral speech and the written language. Since Plato, the first has traditionally been associated with the purely mimetic, the second with the diegetic. Kelman and Donovan, however, reject this distinction, and in HLIW and The Doll's House alight upon a skaz methodology, allowing the demotic to carry out all narrative functions (to a large extent at least). Donovan also explores and then undermines the presumed superiority of the written over the spoken in Hieroglyphics. However, as has been argued implicitly throughout, the attempt to differentiate a dialect from Standard English by representing it phonetically through renegotiated orthographic conventions is problematic to say the least.

A useful summary of this last and highly significant issue can be found in the writing of Duncan McLean, whose opinions on the correlation between dialect and Standard English have already been referred to. Where Kelman uses phonetic representations of dialect, McLean confines himself to Standard 
English; he feels that to represent Scots phonetically is to accede to the assumption that it is somehow inferior to the 'norm'. In short, Standard English should, it could be argued, perform as a 'normalised', neutral discourse which can be conventionally assumed to stand in for any dialect (although Kelman and Donovan will clearly still object to its status as external to a Scottish context). This extract from McLean's story A/deen Soccer Thugs Kill All Visiting Fans is an example of McLean's technique:

In Kenny's fish bar at the top of Bridge Street, there's a lad sitting by himself. He stretches his legs out under the table and kicks the bottom of the empty chair on the other side of it. He drums his fingers on the orange plastic tabletop ... There's an empty coffee cup in front of him; the lad picks it up, looks in it, swirls the dregs around, then replaces it on the saucer. From a bowl at the end of the table beside the sauce bottle and salt, he picks out six packets of sugercubes, packed in twos. He unwraps these, not tearing the wrapping, but unpicking the stuck-down flaps with his fingernails and unfolding the paper and smoothing each piece out on the table-top, before dropping eleven of the cubes into his cup. He chucks the twelfth cube into his mouth and crunches it as he lets the others fall into the cup one by one; as each one is dropped in, he murmurs a name:

Goram, Hunter, Collins, Weir, Kane.$^{29}$

In its matter-of-factness and lack of any obvious agenda other than to recreate a setting in the mind of the reader, this is as close to the elusive goal of neutrality and transparency (espoused by Kelman and, to a lesser extent, Warner) as anything since Hemingway's 'Hills Like White Elephants' or the Kelman of $A$ Chancer. In addition, it is narrated by a voice which, whilst adopting the cadences of the demotic (and thereby validating the demotic as a literary medium), does not attempt to represent its pronunciation or intonation. Direct discourse is represented just as it is in HLIW, without hyphen or inverted commas, implying its equality of status with the narrative voice with which it blends:

She looks up with a start, then smiles. Oh, hiya, David. She comes over and stands by the table. I didn't see you; thought you maybe weren't here yet.

Not here yet! I've been stuck here all afternoon talking to this boring bugger! Hello, says Frankie. ${ }^{30}$

This is a methodology, then, which Kelman has already visited and found wanting, presumably, due, firstly, to its third-party voice paternalism and, secondly, its use of Standard English. However, perhaps the setting of McLean's story, made explicit by the title of the story, should give the reader enough information from which to 'apprehend' the dialect; in other words, the story lets the reader explore the imaginative space between the act of narration, the words on the page and the reading ear. It could be argued that an attempt at literal transcription of dialect is likely to make that dialect seem more alien than the reader would naturally find it in reality; far from aiding and abetting the pursuit of transparency, it in fact compromises it, drawing explicit attention to the authorial voice (and to the presence of the 
puppeteer). In addition, it could be construed as an act of condescension to both the speaker of the dialect and to the reader to alienate the voice in this way, or to give it such artificial prominence. The demotic voice will seem more disconnected from the reader's experience, not less, and a linguistic form which might seem relatively commonplace in real life becomes de-familiarized. As McLean opines, Standard English can reasonably be expected to perform in the manner which is implied by its label: the standard (without its evaluative associations), or the bow against which the string of a dialect, or any speech whatsoever, should automatically pull. When two speakers of different dialects meet, the one will 'hear' the Standard English behind the pronunciation of the other without difficulty. Furthermore, spoken English of any kind is likely to emerge as a dialect when subjected to the kinds of narrow focus implied by some of the experimentation examined in this survey. Of course, none of this directly addresses the ideological objections of writers such as Kelman and Donovan, which will doubtless continue to be held - and with some validity; it does, however, tentatively propose that overt and perhaps undue emphasis on representation of the demotic in narrative fiction is a methodology which can sometimes be as guilty of patronizing both dialect and its speaker as Colonial English can.

The narrative techniques of the texts discussed here are also the result of an intense identification with place, with Glasgow, Edinburgh, Oban, or with Scotland as a whole, and the intrinsically dialogic conditions which exist there. Donovan's goal, like Kelman's and, to a lesser extent, Warner's, is to exploit the particular cultural and linguistic conditions peculiar to her home in order to produce a narrative art form which could adequately aspire to represent them; in other words, to create a distinctive literary voice the better to represent a particular constituency (or a literary equivalent of the processes which take place inside the head of a character from that constituency, and in their daily discourse). The belligerence with which this task must be undertaken if it is to succeed is reflected by Rosemary Goring as she lauds Donovan's rejuvenation of Scots as a representational medium: 'only one problem looms: who, beyond Scotland, will be able to understand us? Are such voices translatable? Perhaps more importantly, do we even care? ${ }^{31}$ Although this survey has not engaged directly with issues pertaining to postcolonial literatures and discourses, it is certainly essential at this late stage to allude to their relevance to this debate, especially with reference to this comment by Goring. It could be argued that it has been the great achievement of many writers commonly associated with the postcolonial area of literary studies that they have managed to communicate the quotidian lives, thoughts and discourse of their own people; in short, to have given a voice to a specific and localized constituency, often with great success and via a large, international and highly eclectic readership. In so doing, these writers have been rightly credited, on one hand, with increasing understanding, knowledge and awareness of such cultures outside of their 
borders, borders both geographical and more abstract. On the other hand, crucially, these writers are also seen to have expanded, rejuvenated and refreshed both the English language and the traditions (and methodologies) of narrative fiction. Their achievements and the extent to which these have become assimilated into both the critical study and production of literature as a whole make the reactions amongst some critics (of whom Goring is a good example) seem unnecessarily polemical and querulous. In answer to Goring's question 'do we even care?' it can surely be agreed that the act of communicating a people's or culture's ipseity through narrative fiction should be thought of as a worthy and laudable achievement, and not one which should be confined by physical borders, or aimed specifically at a local audience. It is surely more productive and mutually enriching to talk back at the centre, not merely ignore it.

\footnotetext{
Notes

${ }^{1}$ From 'Dusty-Fute', D. Kinloch, Dusty-Fute (Middlesex: Vennel Press, 1992).

${ }^{2}$ Some of Kelman's many writings on this topic are collected in Edinburgh Review, 108 (2001). See also essays by Kelman in And the Judges Said...(London: Vintage, 2002), and an essay 'Vernacular' in Brick: A Literary Journal, 51 (Winter 1995).

${ }^{3}$ M. M. Bakhtin, 'Discourse in the Novel', in The Dialogic Imagination: Four Essays, trans. C. Emerson and M. Holquist, ed. M. Holquist (Austin, University of Texas Press, 1981), p. 259.

${ }^{4}$ J. Kelman, How Late It Was, How Late (London: Minerva, 1994). All subsequent references are to this edition.

${ }^{5}$ S. Rimmon-Kenan, Narrative Fiction: Contemporary Poetics (Oxford: Routledge, 1983), p. 109.

${ }^{6}$ Ibid.

${ }^{7}$ K. MacNeill, 'Interview with James Kelman’, Chapman, 57 (Summer 1989), pp. 4-5.

${ }^{8}$ J. Margetts, 'James Kelman: Walking Among the Fires', in Between the Lines, www.thei.aust.com/ isite/btl/btlinkelman.html, retrieved 3 February 2003.

${ }^{9}$ I. Bell, 'James Kelman', The New Welsh Review 3, 2(10) (Autumn 1990), p. 22.

${ }^{10}$ A. O'Hagan, 'The Paranoid Sublime', London Review of Books, 26 May 1994, p. 8.

${ }^{11}$ R. Watson, 'Alien Voices from the Street: Demotic Modernism in Modern Scots Writing', The Yearbook of English Studies, 25 (1995), pp. 148-9.

12 J. Kelman, 'And the Judges Said . .'? Essays (London: Secker and Walburg, 2002), p. 480.

${ }^{13}$ D. McLean, [quoted in] S. Vice, Introducing Bakhtin (Manchester: Manchester University Press, 1997), p. 91.

${ }^{14}$ T. Jones, 'Alan Warner: The Wild Man of Letters', The Independent, 24 May 1998, p. 2.

15 A. Mars-Jones, 'The Island's Best Gimmick is the Mosquito Bite Competition', The Observer, 23 March 1997, p. 2.

${ }^{16}$ A. Warner, Morvern Callar (London, Vintage, 1996), p. 1. All subsequent references are to this edition.

${ }^{17}$ Jones, 'Alan Warner', p. 6.

${ }_{18}$ W. Fiennes, 'Mortal on Hooch', London Review of Books, 20 (15), 30 July 1998, p. 34.

${ }^{19}$ R. Crawford, 'Flower of Scotland', The Independent, 6 June 1998, n.p.

${ }^{20}$ A. Warner, The Sopranos (London, Jonathan Cape, 1998), p. 80. All subsequent references are to this edition.

${ }^{21}$ E. Young, 'For a wee bit of sparkle', The Guardian, 20 June 1998, p. 10.

${ }^{22}$ D. Cunningham, 'A Wee Gem of a Story Book', The Scotsman, 28 July 2001, p. 14.

${ }^{23}$ R. Goring,'Time to Lose the Chip on our Shoulder and Think Bilingual', The Glasgow Herald, 15 March 2003, p. 12.

${ }^{24}$ Ibid.

${ }^{25}$ R. Goring, 'She's Talking our Language Now', The Glasgow Herald, 4 January 2003, p. 14.
} 
${ }^{26}$ A. Donovan, Hieroglyphics and Other Stories (Edinburgh: Canongate, 2001), p. 1. All subsequent references are to this edition.

${ }^{27}$ Goring, 'Time to Lose the Chip', p. 12.

${ }^{28}$ D. McLean, [quoted in] Vice, Introducing Bakhtin, p. 91.

${ }^{29}$ D. McLean, 'A/deen Soccer Thugs Kill All Visiting Fans', Bucket of Tongues (London: Minerva, 1994), p. 29.

${ }^{30}$ Ibid., p. 39.

${ }^{31}$ Op. cit. [Goring].

\section{Bibliography}

\section{PRIMARY TEXTS}

Donovan, A., Hieroglyphics and Other Stories (Edinburgh: Cannongate Books, 2001).

Kelman, J., How Late It Was, How Late (London: Minerva, 1994).

Warner, A., Morvern Callar (London:Vintage, 1996).

Warner, A., The Sopranos (London: Jonathan Cape, 1998).

\section{SECONDARY TEXTS}

Donovan, A., Buddha Da (Edinburgh: Cannongate Books, 2004).

Kelman, J., The Busconductor Hines (London: Phoenix, 1984).

Kelman, J., A Chancer (London: Minerva, 1985).

Kelman, J., Not Not While the Giro (London: Minerva, 1989).

Kelman, J., Some Recent Attacks: Essays Cultural and Political (Stirling: AK Press, 1992).

Kelman, J., 'And the Judges Said . . .': Essays (London: Secker and Walburg, 2002).

McLean, D., Bucket of Tongues (London: Minerva, 1994).

Warner, A., These Demented Lands (London:Vintage, 1998).

\section{OTHER REFERENCES AND SUGGESTED FURTHER READING}

Bakhtin, M., The Dialogic Imagination: Four Essays, trans. C. Emerson and M. Holquist, ed. M. Holquist (Austin: University of Texas Press, 1981).

Bell, I., 'James Kelman', The New Welsh Review 3, 2 (10) (Autumn 1990), pp. 18-22.

Bittenbender, J. C., 'Silence, Censorship, and the Voices of Skaz in the Fiction of James Kelman', Bucknell Review 43(2) 2000, pp. 150-165.

Cobley, P., Narrative, 'The New Critical Idiom' series, series ed. J. Drakakis (London: Routledge, 2001).

Crawford, R., 'Flower of Scotland', The Independent, 6 June 1998, p. 9.

Cunningham, D., 'A Wee Gem of a Story Book', The Scotsman, 28 July 2001, p. 14.

Edinburgh Review, 108 (2001).

Fiennes, W., 'Mortal on Hooch', London Review of Books, 20 (15), 30 July 1998, p. 34.

Goring, R., 'She's Talking our Language Now', The Glasgow Herald, 4 January 2003, p. 14.

Goring, R., 'Time to Lose the Chip on our Shoulder and Think Bilingual', The Glasgow Herald, 15 March 2003, p. 12.

Hill, C., 'Quietly Impressive Debut by a Subtle Lover of Language', The Birmingham Post, 23 June 2001, p. 52.

Jamieson, T., 'This Demented Man', The Herald (Glasgow), 30 May 1998, p. 11.

Jones, T., 'Alan Warner: The Wild Man of Letters', The Independent, 24 May 1998, p. 2.

Kelman, J., 'Vernacular', Brick: A Literary Journal 51 (Winter 1995), pp. 68-9.

Kinloch, D., Dusty-Fute (Middlesex: Vennel Press, 1992).

Lane, R. J., R. Mengham and P. Tew, ed., Contemporary British Fiction (Cambridge: Polity Press, 2003).

McGlynn, M., “'Middle-Class Wankers” and Working-Class Texts: The Critics and James Kelman', Contemporary Literature 43(1) (2002), pp. 50-84. 
McLean, D., 'James Kelman Interviewed', Edinburgh Review 71 (1995), pp. 64-80.

MacNeill, K., 'Interview with James Kelman', Chapman 57 (Summer 1989), pp. 1-17.

Margetts, J., 'James Kelman: Walking Among the Fires', in Between the Lines, www.thei.aust.com/isite/btl/btlinkelman.html, retrieved 3 February 2003.

Mars-Jones, A., 'In Holy Boozers', Times Literary Supplement, 1 April 1994, n.p.

Milne, D., 'James Kelman: Dialectics of Urbanity', Swansea Review (1994), pp. 393-407.

O’Hagan, A., 'The Paranoid Sublime', London Review of Books, 26 May 1994, p. 8.

Pitchford, N., 'How Late it was for England: James Kelman's Scottish Booker Prize', Contemporary Literature 41(1) (Spring 2000), pp. 693-725.

Rimmon-Kenan, S., Narrative Fiction: Contemporary Poetics (Oxford: Routledge, 1983).

Vice, S., Introducing Bakhtin (Manchester: Manchester University Press, 1997).

Wallace, G. and R. Stevenson, ed., The Scottish Novel Since the Seventies (Edinburgh: Edinburgh University Press, 1993).

Watson, R., 'Alien Voices from the Street: Demotic Modernism in Modern Scots Writing', The Yearbook of English Studies 25 (1995), pp. 141-55.

Young, E., 'For a wee bit of sparkle', The Guardian, 20 June 1998, p. 10. 